\title{
Article \\ Phenolic Characterization and Bioactivity of Fennel Seed (Foeniculum vulgare Mill.) Extracts Isolated by Microwave-Assisted and Conventional Extraction
}

\author{
Valentina Malin ${ }^{1}$, Ivona Elez Garofulić ${ }^{2, *}$, Maja Repajić ${ }^{2} \mathbb{D}$, Zoran Zorić ${ }^{2}$, Sandra Pedisić ${ }^{2} \mathbb{D}$, Meta Sterniša $^{1}(\mathbb{D}$, \\ Sonja Smole Možina ${ }^{1}$ (D) and Verica Dragović-Uzelac ${ }^{2}$ (D)
}

1 Biotechnical Faculty, University of Ljubljana, 1000 Ljubljana, Slovenia; valentina.malin@bf.uni-lj.si (V.M.); meta.sternisa@bf.uni-lj.si (M.S.); sonja.smole-mozina@bf.uni-lj.si (S.S.M.)

2 Faculty of Food Technology and Biotechnology, University of Zagreb, 10000 Zagreb, Croatia; maja.repajic@pbf.unizg.hr (M.R.); zoran.zoric@pbf.unizg.hr (Z.Z.); sandra.pedisic@pbf.unizg.hr (S.P.); vdragov@pbf.hr (V.D.-U.)

* Correspondence: ivona.elez@pbf.unizg.hr

check for updates

Citation: Malin, V.; Elez Garofulić, I.; Repajić, M.; Zorić, Z.; Pedisić, S.; Sterniša, M.; Smole Možina, S.;

Dragović-Uzelac, V. Phenolic

Characterization and Bioactivity of Fennel Seed (Foeniculum vulgare Mill.) Extracts Isolated by MicrowaveAssisted and Conventional

Extraction. Processes 2022, 10, 510

https://doi.org/10.3390/pr10030510

Academic Editors: Jasna

Čanadanović-Brunet and

Irena Zizovic

Received: 30 November 2021

Accepted: 2 March 2022

Published: 3 March 2022

Publisher's Note: MDPI stays neutral with regard to jurisdictional claims in published maps and institutional affiliations.

Copyright: (C) 2022 by the authors. Licensee MDPI, Basel, Switzerland. This article is an open access article distributed under the terms and conditions of the Creative Commons Attribution (CC BY) license (https:// creativecommons.org/licenses/by/ $4.0 /)$.
Abstract: The aim of this study was to evaluate the effectiveness of microwave-assisted extraction (MAE) as an environmentally friendly approach compared to conventional heat-reflux extraction (CE) for the isolation of fennel (Foeniculum vulgare Mill.) seed polyphenols and to assess the bioactivity of the obtained extracts. Water, ethanol $(30 \%, v / v)$ and acetone $(30 \%, v / v)$ were used as extraction solvents, and the extraction was carried out varying the temperature $\left(40,60\right.$ and $\left.80^{\circ} \mathrm{C}\right)$, irradiation time (5 and $10 \mathrm{~min}$ ) and microwave power $(300$ and $600 \mathrm{~W})$. According to the total phenolic content (TPC), $30 \%$ acetone at $80{ }^{\circ} \mathrm{C}$ after $5 \mathrm{~min}$ of irradiation at $300 \mathrm{~W}$ proved to be the optimal MAE conditions for obtaining the highest yield of polyphenols. The phenolic profile of both extracts comprised 21 compounds, with cinnamic acids and flavonols being the most abundant. When compared to CE, the MAE extract showed a lower amount of TPC as well as the sum of all identified individual phenols, although both extracts showed similar antioxidant capacity. The antimicrobial activity of the extract with the highest phenolic content was weak, showing inhibitory activity only against Pseudomonas fragi, Shewanella putrefaciens and Campylobacter jejuni strains, while Gram-positive bacteria and yeasts were not sensitive to the extract.

Keywords: Foeniculum vulgare Mill.; fennel seeds; microwave-assisted extraction; heat-reflux extraction; polyphenols; UPLC-MS/MS; antioxidant capacity; ORAC; antimicrobial activity; microdilution

\section{Introduction}

Fennel (Foeniculum vulgare Mill.) is a biennial medicinal and aromatic plant from the Apiaceae family [1], widespread in the Mediterranean area and known for its yellow flowers grouped in umbels, feathery leaves, hollow stem and aromatic seeds. Along with traditional use for culinary purposes and flavoring, due to its beneficial effects on human health the plant is widely used in traditional medicine to relieve colic in infants, to relieve respiratory and gastrointestinal disorders, and to prevent various diseases caused by oxidative stress-cancer, cardiovascular diseases, inflammatory diseases. It is also used as a galactagogue for lactating mothers [2,3]. All these pharmacological properties as well as its antimicrobial and antioxidant activity are attributed to its high content of different classes of valuable bioactive compounds, such as polyphenols and volatile compounds [2]. Furthermore, fennel seeds represent an interesting, easily accessible and inexpensive potential source of bioactives that could be used in the food industry to improve food quality and safety. Although they are mainly used for their essential oil abundance, they also present a valuable source of compounds such as fatty acids, sterols and polyphenols $[4,5]$. 
Due to the firm outer coating and structure of the fennel seeds, the isolation of its phenolic compounds is very demanding and therefore it is of crucial importance to choose an efficient extraction solvent and technique and to define optimal conditions that will ensure high extraction yields. The choice of the appropriate extraction technique is very important, as it strongly influences the quantitative and qualitative composition of the extract.

Extraction of phenolic compounds can be carried out using conventional techniques and by recently developed, advanced techniques that are recognized as "green « or »ecofriendly« (e.g., microwave-assisted extraction, pressurized liquid extraction, ultrasoundassisted extraction). Advanced techniques have a great potential application in the extraction of phenols, as they ensure the extraction with reduced consumption of organic and synthetic chemicals, shorter extraction time and lower extraction temperatures, automation, higher extraction yields, better quality of extracts and greater safety [6]. Microwaveassisted extraction (MAE) is one of the most promising modern extraction techniques [7]. The method is based on the heating of the sample through the mechanisms of ionic conduction and dipole rotation, which leads to the disruption of hydrogen bonds, thus increasing the penetration of the solvent into the sample matrix and enabling the extraction of the compounds [8]. However, as previous studies have shown [9-16], in order to exploit the full potential of the technique, extraction parameters such as solvent, temperature, irradiation time and microwave power should be optimized.

Scientific interest in fennel seeds has been largely focused on their essential oils [17-21] applying advanced extraction techniques such as supercritical fluid extraction [22-24], while published research on the isolation of phenolic compounds from fennel seeds, especially the comparison of different extraction techniques and applied extraction conditions, is quite limited. Recently, only the study by Akhtar et al. (2020) [1] compared MAE with conventional Soxhlet and cold maceration extraction techniques and optimized MAE using water as an extraction solvent. MAE proved to be an energy efficient and rapid method for the isolation of phytochemicals from fennel seeds, giving higher extraction yields when compared to the applied conventional techniques. However, the study did not include the effect of the extraction solvent and overall impact of the technique on the composition of individual compounds in obtained extracts.

Therefore, the aim of this work was to evaluate the influence of temperature, irradiation time, microwave power and extraction solvent on the recovery of phenols from fennel seeds during MAE. Moreover, the goal was also to compare MAE with conventional heatreflux extraction and to determine the influence of the applied technique on the phenolic composition of extracts as well as on their antioxidant capacity and antimicrobial activity.

\section{Materials and Methods}

\subsection{Plant Material}

Commercially available dried fennel seeds (Suban Ltd., Strmec, Croatia) of Egyptian origin were used in this study. Moisture content of the seeds was determined by drying at $103 \pm 2{ }^{\circ} \mathrm{C}$ to a constant mass and was less than $2 \%$. The seeds were milled using a grinder (GT11, Tefal, Rumilly, France) and stored in a glass jar at room temperature until use. The particle size was determined by laser particle-size analyzer (Master-sizer 2000, Malvern Instruments, Malvern, Worcestershire, UK) showing particle size d (0.5) to be $658.4 \mu \mathrm{m}$.

\subsection{Chemicals and Standards}

Ethanol (96\%) was purchased from Kefo (Ljubljana, Slovenia), acetone (100\%) from Gram-Mol (Zagreb, Croatia), Folin-Ciocalteu reagent and dimethyl sulfoxide (DMSO) and sodium chloride $(\mathrm{NaCl})$ from Merck (Darmstadt, Germany). Anhydrous sodium carbonate $\left(\mathrm{Na}_{2} \mathrm{CO}_{3}\right)$ was purchased from Kemika (Zagreb, Croatia). 2,2'-Azobis (2-amidinopropane) hydrochloride (AAPH), 2-p-iodophenyl-3-p-nitrophenyl-5-phenyl tetrazolium chloride (INT) and resazurin from Sigma Aldrich (St. Louis, MO, USA), fluorescin sodium salt $\left(\mathrm{C}_{20} \mathrm{H}_{10} \mathrm{NaO}_{5}\right)$ from Honeywell Riedel-de-Haën (Bucharest, Romania), phosphate buffer (pH 7.0) and trolox (6-hydroxy-2,5,7,8-tetramethylchroman-2-carboxylic acid) from Acros 
Organics (Thermo Fisher Scientific, Geel, Belgium). Formic acid and acetonitrile for UPLC analysis were HPLC grade, purchased from BDH Prolabo (Lutterworth, UK).

UPLC standards quercetin-3-glucoside, kaempferol-3-rutinoside, gallic acid, chlorogenic acid, quinic acid and rosmarinic acid were purchased from Sigma Aldrich (St. Louis, MO, USA), apigenin and esculetin from Extrasynthese (Genay, France), and quercein-3rutinoside from Acros Organics (Geel, Belgium). Distilled water was of Milli-Q quality (Millipore, Bedford, NY, USA).

Tryptic Soy Agar, Tryptic Soy Broth and Karmali were purchased from Biolife (Milan, Italy), Malt Extract Agar and Malt Extract Broth from Merck (Darmstadt, Germany), Mueller-Hinton Agar from bioMérieux (Marcy-l'Étoile, France) and Mueller-Hinton Broth from Oxoid (Hampshire, UK).

\subsection{Microbial Strains and Growth Conditions}

The experiment included the following food spoilage and foodborne pathogen microbial strains: Listeria innocua ŽM39, Staphylococcus aureus ATCC 25923, Escherichia coli ATCC 11229, Pseudomonas fragi ATCC 4973, Shewanella baltica NCTC 10735, Shewanella putrefaciens ŽM654, Shewanella xiamenensis ŽM655, Campylobacter jejuni NCTC 11168, Candida albicans ZIM 2202 and Pichia anomala ZIM 1769. Microorganisms were obtained from the collection of the Laboratory for Food Microbiology at the Department of Food Science, Biotechnical Faculty, University of Ljubljana, Slovenia (designation ŽM), the Slovenian Collection of Industrial Microorganisms (designation ZIM), the American Type Culture Collection (designation ATCC) and the National Collection of Type Cultures (designation NCTC). The strains were kept at $-80^{\circ} \mathrm{C}$ in suitable broth media (Tryptic Soy Broth, Mueller-Hinton Broth or Malt Extract Broth) supplemented with 20\% glycerol (Kemika, Zagreb, Croatia).

For revitalization and cultivation of L. innocua, S. aureus and E. coli, Tryptic Soy Agar was used overnight at $37^{\circ} \mathrm{C}$, while for P. fragi, S. putrefaciens and S. xiamenensis the same was applied overnight at $30^{\circ} \mathrm{C}$. C. jejuni was revitalized by Karmali, while cultivation was done on Mueller-Hinton Agar overnight at $42{ }^{\circ} \mathrm{C}$ under microaerophilic conditions $\left(5 \% \mathrm{O}_{2}, 10 \% \mathrm{CO}_{2}, 85 \% \mathrm{~N}_{2}\right)$. C. albicans and P. anomala were revitalized and cultivated on Malt Extract Agar for $48 \mathrm{~h}$ at $30^{\circ} \mathrm{C}$. After revitalization, the culture was transferred to an appropriate volume of $0.9 \% \mathrm{NaCl}$ solution to obtain an optical density (OD) at $600 \mathrm{~nm}$ of $0.090-0.110$ (for bacterial strains) or 0.170-0.200 (for yeast strains). The suspension was afterwards diluted 100-fold in broth media (Tryptic Soy Broth for all bacteria except $C$. jejuni where Mueller-Hinton Broth was used, Malt Extract Broth for yeast) in order to obtain an inoculum concentration of approximately $10^{5} \mathrm{CFU} / \mathrm{mL}$. The plate count method was used for determination of the exact concentration of microbial cells in the inocula.

\subsection{Phenolics Extraction and Analysis}

\subsubsection{Microwave-Assisted Extraction (MAE)}

MAE was performed in a microwave reactor (Ethos Easy Milestone Connect, Advanced microwave digestion system, Milestone Srl, Bergamo, Italy) equipped with extraction cells containing a magnetic stirrer where approximately $1 \mathrm{~g}$ of sample was mixed with $40 \mathrm{~mL}$ of the extraction solvent. Constant pre-extraction parameters were as follows: time required for temperature achievement $-2 \mathrm{~min}$, ventilation after the extraction $-1 \mathrm{~min}$ and stirring $-50 \%$. The experiments were carried out varying the following parameters: extraction solvent [water, 30\% aqueous ethanol $(v / v)$ and $30 \%$ aqueous acetone $(v / v)$ ], temperature $\left(40,60\right.$ and $80^{\circ} \mathrm{C}$ ), irradiation time (5 and $10 \mathrm{~min}$ ) and microwave power $(300$ and $600 \mathrm{~W}$ ), according to the experimental design. Subsequently, the extracts were filtered into $50 \mathrm{~mL}$ volumetric flasks, made up to volume with appropriate solvent and transferred to Falcon tubes. The extracts were stored at $-18^{\circ} \mathrm{C}$ in a nitrogen gas atmosphere until analyzed. 


\subsubsection{Conventional Heat-Reflux Extraction (CE)}

For comparison with MAE, fennel seeds were extracted by conventional heat-reflux extraction with the solvent determined as optimal during MAE ( $30 \%$ acetone). Approximately $1 \mathrm{~g}$ of ground plant sample was weighed into a round bottom flask and mixed with $40 \mathrm{~mL}$ of extraction solvent. The flask was placed under a reflux condenser and heated over a flame for $20 \mathrm{~min}$ from the onset of boiling. The extract was then filtered into a volumetric flask $(50 \mathrm{~mL})$, made up to volume with solvent and transferred into Falcon tubes. The extracts were stored at $-18{ }^{\circ} \mathrm{C}$ in a nitrogen gas atmosphere until analyzed.

\subsubsection{Total Phenolic Content (TPC)}

TPC was determined using the Folin-Ciocalteu method previously described by Shortle et al. (2014) [25]. A volume of $100 \mu \mathrm{L}$ of the extract was mixed with $200 \mu \mathrm{L}$ of the Folin-Ciocalteu reagent and $2 \mathrm{~mL}$ of distilled water. After $3 \mathrm{~min}, 1 \mathrm{~mL}$ of $20 \% \mathrm{Na}_{2} \mathrm{CO}_{3}$ solution was added. The mixture was thermostated in a water bath $\left(25 \mathrm{~min}, 50{ }^{\circ} \mathrm{C}\right)$. The absorbance was measured at $765 \mathrm{~nm}$. The blank sample contained solvent instead of the extract. TPC values were calculated using the gallic acid standard calibration curve $\left(y=0.0035 x, R^{2}=0.9995\right)$. Results were expressed as mg gallic acid equivalent (GAE)/100 g dry sample as the average of two measurements.

\subsubsection{UPLC/ESI MS² Analysis}

The phenolic composition of the extracts was determined by UPLC/ESI MS ${ }^{2}$, as previously described by Elez Garofulić et al. (2018) [26], using an Agilent 1290 series RRLC instrument (Agilent, Santa Clara, CA, USA) coupled to a triple quadropole spectrometer (6430) with an ESI ion source connected to a binary pump, with an autosampler and thermostated column compartment. A Zorbax Eclipse Plus C18 column $(1.8 \mu \mathrm{m}, 100 \times 2.1 \mathrm{~mm}$ I.D.) with a target temperature of $35^{\circ} \mathrm{C}$ and an injection volume of $2.5 \mu \mathrm{L}$ was used for separation. Ionization was performed by ESI in positive and negative modes $(\mathrm{m} / z 100$ to $1000)$ using nitrogen $(99.999 \%$, Messer, Croatia) as inducing cone and collision gas under the following conditions: positive/negative capillary voltage, 4000/3500 V; drying gas temperature of $300{ }^{\circ} \mathrm{C}$ with a flow rate of $11 \mathrm{~L} / \mathrm{h}$ and nebulizer pressure of $40 \mathrm{psi}$. Data were collected in the multiple reactions monitoring (MRM) mode. Phenols were identified and quantified using the calibration curves of the standards: gallic, chlorogenic, quinic and rosmarinic acid, rutin, quercetin-3-glucoside, kaempferol-3-rutinoside, apigenin and esculetin. The quality parameters of the analytical method including calibration curves and instrumental detection (LOD), and quantification (LOQ) limits were reported previously, as well as the MS data including cone voltage, collision energy and ionization mode [26]. For compounds for which commercial standards were not available, identification was based on mass spectral data (Supplementary File S1) and literature reports of mass fragmentation patterns, while quantification was performed as follows: $p$-hydroxybenzoic acid-O-glucoside corresponding to the gallic acid calibration curve, neochlorogenic acid, dicaffeoylquinic acid derivate and caffeoylquinic acid derivates corresponding to the chlorogenic acid, feruloylquinic acid and $p$-coumaroylquinic acid derivates corresponding to the quinic acid calibration curve, isorhamnetin hexosides and quercetin glucuronide and hexoside corresponding to the quercetin-3-glucoside, kaempferol hexoside and glucuronide corresponding to the keampferol-3-rutinoside, apigenin glucuronide corresponding to the apigenin and esculetin hexoside corresponding to the esculetin calibration curve. All results were expressed in mg per $100 \mathrm{~g}$ of sample as the mean of two replicates.

\subsubsection{Antioxidant Capacity (Oxygen Radical Antioxidant Capacity-ORAC)}

ORAC analysis was performed according to Elez Garofulić et al. (2020) [14]. An automatic plate reader (BMG LABTECH, Offenburg, Germany) with 96-well plates was used for analysis and data were analyzed using MARS 2.0 software. Appropriately diluted samples were added to a black plate containing a fluorescein solution $(70.3 \mathrm{nM})$ and incubated at $37^{\circ} \mathrm{C}$ for $30 \mathrm{~min}$. After the first three cycles (representing the baseline signal), peroxyl 
radical generation was initiated by the addition of $240 \mathrm{mM}$ AAPH into each well. Different dilutions of Trolox (3.12-103.99 $\mu \mathrm{M})$ were used on each plate as a reference standard. Fluorescence intensity (excitation at $485 \mathrm{~nm}$ and emission at $528 \mathrm{~nm}$ ) was monitored every $90 \mathrm{~s}$ for a total measurement time of $120 \mathrm{~min}$ and the results were expressed as mean value of two replicates \pm standard deviation in $\mu \mathrm{mol}$ of Trolox equivalents (TE) $/ 100 \mathrm{~g}$.

\subsection{Antimicrobial Activity}

For microbiological analyses, the $30 \%$ acetone CE extract with the highest phenolic content was used. The solvent was removed using a vacuum concentrator (SAVANT SPD 2010 SpeedVac Concentrator, Thermo Fisher Scientific Inc., Sunnyvale, CA, USA) under the following conditions: temperature $50{ }^{\circ} \mathrm{C}$, vacuum level 10 Torr and vacuum ramp rate 3 . Dried extract was diluted in $100 \%$ DMSO in order to prepare stock solution at a concentration of $100 \mathrm{mg} / \mathrm{mL}$ and stored at $-20^{\circ} \mathrm{C}$ until analysis.

A broth microdilution method was used to determine minimal inhibitory concentrations (MICs) of the extracts on the tested microorganisms. The method was performed according to Klančnik et al. (2010) [27]. 2-fold dilutions were prepared in broth media. The minimal inhibitory concentration (MIC) was the lowest concentration of the extract at which no microbial growth was observed after adding INT or, in the case of C. jejuni, resazurin as indicators. The minimal bactericidal or fungicidal concentration (MBC/MFC) was the lowest concentration at which no microbial growth was observed on agar plates after subcultivation of bacterial suspension at which MIC was determined and higher concentrations. The analyses were performed in three technical and two biological replicates.

\subsection{Statistical Analysis}

To optimize the conditions of MAE, statistical analysis was performed using Statistica ver. 10.0 software (StatSoft Inc., Tulsa, OK, USA). A mixed 2- and 3-level full factorial design with 36 experimental trials was used to evaluate the effect of four independent variables (solvent, temperature, irradiation time and microwave power) on the TPC values of fennel seeds extracts (Table 1). Normality and homoscedasticity of data were tested using Shapiro-Wilk's test and Levene's test, respectively. Data were analyzed using ANOVA (parametric data) or the Kruskal-Wallis test (nonparametric data) when appropriate, while means within groups were compared using Tukey's HSD test or the Kruskal-Wallis test. The significance level of $p \leq 0.05$ was assigned for all tests. Results of statistical analysis are presented as least squares means (LS) \pm standard errors (SE). For comparison of effectiveness of MAE and CE techniques in terms of TPC, total UPLC ESI MS² identified compounds and ORAC value, means were compared using one-way analysis of variance (ANOVA) and post hoc Tukey's HSD test.

Table 1. TPC in fennel seeds extracts obtained under different conditions of MAE according to the full factorial design.

\begin{tabular}{|c|c|c|c|c|}
\hline Solvent & Temperature, ${ }^{\circ} \mathrm{C}$ & Microwave Power, W & Time, min & TPC, mg GAE/100 g \\
\hline \multirow{12}{*}{ Water } & \multirow{4}{*}{40} & \multirow[b]{2}{*}{300} & 5 & $511.6 \pm 12.8$ \\
\hline & & & 10 & $381.2 \pm 5.0$ \\
\hline & & \multirow{2}{*}{600} & 5 & $431.2 \pm 10.6$ \\
\hline & & & 10 & $455.0 \pm 8.2$ \\
\hline & \multirow{4}{*}{60} & \multirow{2}{*}{300} & 5 & $482.4 \pm 18.7$ \\
\hline & & & 10 & $478.9 \pm 9.4$ \\
\hline & & \multirow[b]{2}{*}{600} & 5 & $508.0 \pm 7.0$ \\
\hline & & & 10 & $491.1 \pm 20.5$ \\
\hline & \multirow{4}{*}{80} & \multirow{2}{*}{300} & 5 & $605.2 \pm 13.4$ \\
\hline & & & 10 & $486.5 \pm 18.8$ \\
\hline & & \multirow{2}{*}{600} & 5 & $599.3 \pm 1.0$ \\
\hline & & & 10 & $465.1 \pm 3.9$ \\
\hline
\end{tabular}


Table 1. Cont.

\begin{tabular}{|c|c|c|c|c|}
\hline Solvent & Temperature, ${ }^{\circ} \mathrm{C}$ & Microwave Power, W & Time, min & TPC, mg GAE/100 g \\
\hline \multirow{12}{*}{$\begin{array}{c}\text { Ethanol, } \\
30 \% \\
(v / v)\end{array}$} & \multirow{4}{*}{40} & \multirow{2}{*}{300} & 5 & $316.4 \pm 9.1$ \\
\hline & & & 10 & $295.7 \pm 0.9$ \\
\hline & & \multirow[b]{2}{*}{600} & 5 & $305.3 \pm 9.2$ \\
\hline & & & 10 & $292.9 \pm 3.9$ \\
\hline & \multirow{4}{*}{60} & \multirow[b]{2}{*}{300} & 5 & $267.2 \pm 10.7$ \\
\hline & & & 10 & $252.8 \pm 7.6$ \\
\hline & & \multirow[b]{2}{*}{600} & 5 & $237.3 \pm 10.5$ \\
\hline & & & 10 & $372.2 \pm 6.6$ \\
\hline & \multirow{4}{*}{80} & \multirow[b]{2}{*}{300} & 5 & $610.9 \pm 8.1$ \\
\hline & & & 10 & $544.7 \pm 4.8$ \\
\hline & & \multirow{2}{*}{600} & 5 & $513.4 \pm 12.5$ \\
\hline & & & 10 & $533.4 \pm 1.9$ \\
\hline \multirow{12}{*}{$\begin{array}{c}\text { Acetone, } \\
30 \% \\
(v / v)\end{array}$} & \multirow{4}{*}{40} & \multirow{2}{*}{300} & 5 & $541.1 \pm 24.0$ \\
\hline & & & 10 & $524.7 \pm 2.8$ \\
\hline & & \multirow[b]{2}{*}{600} & 5 & $525.8 \pm 7.7$ \\
\hline & & & 10 & $644.7 \pm 15.1$ \\
\hline & \multirow{4}{*}{60} & \multirow{2}{*}{300} & 5 & $676.9 \pm 14.1$ \\
\hline & & & 10 & $553.5 \pm 18.4$ \\
\hline & & \multirow{2}{*}{600} & 5 & $547.5 \pm 16.8$ \\
\hline & & & 10 & $706.2 \pm 19.0$ \\
\hline & \multirow{4}{*}{80} & \multirow{2}{*}{300} & 5 & $608.2 \pm 4.9$ \\
\hline & & & 10 & $667.0 \pm 27.2$ \\
\hline & & \multirow{2}{*}{600} & 5 & $565.3 \pm 14.5$ \\
\hline & & & 10 & $534.5 \pm 1.0$ \\
\hline
\end{tabular}

Results are expressed as mean \pm standard deviation.

\section{Results and Discussion}

\subsection{MAE Optimization}

Since fennel seeds have a firm outer structure, it is important to optimize the extraction process of polyphenols in order to obtain high yield. Therefore, MAE was carried out varying the extraction solvent, temperature, irradiation time and microwave power to observe the influence of extraction parameters on the recovery of phenolic compounds from fennel seeds. For the solvent effect, 30\% aqueous solutions of ethanol and acetone were compared to water, according to previous literature reports confirming the suitability of these binary solvent systems for the isolation of plant polyphenols [15,28-30]. The temperature, time and microwave power span taken into consideration were selected based upon previous research on MAE of polyphenols [14,15,31]. Table 1 shows the results of TPC determination in the obtained extracts.

TPC of MAE extracts ranged from $237.3 \pm 10.5$ to $706.2 \pm 19.0 \mathrm{mg} \mathrm{GAE} / 100 \mathrm{~g}$, which is in agreement with the results of Roby et al. (2013) [32], where maceration during $72 \mathrm{~h}$ was applied. Repajić et al. (2020) [33] reported lower TPC values (145.27-474.21 mg GAE/100 g) for the extractions performed with pressurized liquid extraction. Higher TPC was reported in methanolic and ethanolic fennel seed extracts from Pakistan (627.21 \pm 18.36 $967.50 \pm 35.51 \mathrm{mg} \mathrm{GAE} / 100 \mathrm{~g}$ ) [34] and in methanolic extracts from Iran and Europe (14 $\pm 0.18-262 \pm 0.91 \mathrm{mg} / \mathrm{g}$ of dry weight (dw) [35], both isolated by maceration during 8 and $24 \mathrm{~h}$, respectively. These differences in literature reports can surely be attributed to different extraction methods and extraction solvents as well as to the variations in plant material itself and related to the influence of growing conditions, climate, soil and plant genotype.

Statistical analysis (Table 2) showed a significant influence of extraction solvent and temperature on TPC of fennel seeds during MAE, while irradiation time and microwave power showed no significant effect. 
Table 2. TPC in fennel seeds extracts influenced by the main parameters of MAE.

\begin{tabular}{|c|c|}
\hline MAE Parameters & TPC, mg GAE/100 g \\
\hline Solvent & $p<0.01 *$ \\
\hline Water & $491.3 \pm 12.7^{\mathrm{a}}$ \\
\hline Ethanol $(30 \%, v / v)$ & $378.5 \pm 26.6^{\mathrm{a}}$ \\
\hline Acetone $(30 \%, v / v)$ & $591.3 \pm 13.4^{\mathrm{b}}$ \\
\hline Temperature, ${ }^{\circ} \mathrm{C}$ & $p<0.01 *$ \\
\hline 40 & $435.5 \pm 23.5^{a}$ \\
\hline 60 & $464.5 \pm 31.1^{\mathrm{a}}$ \\
\hline 80 & $561.1 \pm 11.1^{b}$ \\
\hline Microwave power, $\mathrm{W}$ & $p=0.64$ \\
\hline 300 & $489.1 \pm 22.1^{a}$ \\
\hline 600 & $484.9 \pm 20.1^{\mathrm{a}}$ \\
\hline Irradiation time, min & $p=0.49$ \\
\hline 5 & $491.8 \pm 21.3^{a}$ \\
\hline 10 & $482.2 \pm 20.9^{a}$ \\
\hline \multicolumn{2}{|l|}{ Solvent $\times$ temperature, ${ }^{\circ} \mathrm{C}$} \\
\hline & $p<0.01^{*}$ \\
\hline Water $\times 40$ & $444.7 \pm 17.9 \mathrm{ab}$ \\
\hline Ethanol $(30 \%, v / v) \times 40$ & $302.5 \pm 3.9^{a}$ \\
\hline Acetone $(30 \%, v / v) \times 40$ & $\begin{array}{c}559.1 \pm 19.2^{\mathrm{b}} \\
p<0.01^{*}\end{array}$ \\
\hline Water $\times 60$ & $490.1 \pm 5.9^{a b}$ \\
\hline Ethanol $(30 \%, v / v) \times 60$ & $282.4 \pm 20.2^{\mathrm{a}}$ \\
\hline Acetone $(30 \%, v / v) \times 60$ & $\begin{array}{c}621.0 \pm 27.3^{b} \\
p=0.17\end{array}$ \\
\hline Water $\times 80$ & $539.0 \pm 24.3^{\mathrm{a}}$ \\
\hline Ethanol $(30 \%, v / v) \times 80$ & $550.6 \pm 14.0^{\mathrm{a}}$ \\
\hline Acetone $(30 \%, v / v) \times 80$ & $593.7 \pm 19.3^{\mathrm{a}}$ \\
\hline \multicolumn{2}{|l|}{ Solvent $\times$ microwave power, $\mathrm{W}$} \\
\hline & $p<0.01 *$ \\
\hline Water $\times 300$ & $490.9 \pm 20.0^{a}$ \\
\hline Ethanol $(30 \%, v / v) \times 300$ & $381.3 \pm 42.8^{\mathrm{a}}$ \\
\hline Acetone $(30 \%, v / v) \times 300$ & $\begin{array}{c}595.2 \pm 18.5^{\mathrm{b}} \\
p<0.01^{*}\end{array}$ \\
\hline Water $\times 600$ & $491.6 \pm 16.5^{\mathrm{a}}$ \\
\hline Ethanol $(30 \%, v / v) \times 600$ & $375.7 \pm 33.7^{\mathrm{a}}$ \\
\hline Acetone $(30 \%, v / v) \times 600$ & $587.3 \pm 20.1^{b}$ \\
\hline \multicolumn{2}{|l|}{ Solvent $\times$ irradiation time, $\min$} \\
\hline & $p<0.01^{*}$ \\
\hline Water $\times 5$ & $522.9 \pm 18.8^{a b}$ \\
\hline Ethanol $(30 \%, v / v) \times 5$ & $375.1 \pm 41.6^{\mathrm{a}}$ \\
\hline Acetone $(30 \%, v / v) \times 5$ & $\begin{array}{c}577.5 \pm 15.8^{\mathrm{b}} \\
p<0.01^{*}\end{array}$ \\
\hline Water $\times 10$ & $459.6 \pm 11.5^{\mathrm{a}}$ \\
\hline Ethanol $(30 \%, v / v) \times 10$ & $381.9 \pm 35.2^{\mathrm{a}}$ \\
\hline Acetone $(30 \%, v / v) \times 10$ & $605.1 \pm 21.5^{b}$ \\
\hline
\end{tabular}


Table 2. Cont.

\begin{tabular}{|c|c|}
\hline MAE Parameters & TPC, mg GAE/100 g \\
\hline \multicolumn{2}{|c|}{ Temperature, ${ }^{\circ} \mathrm{C} \times$ microwave power, $\mathrm{W}$} \\
\hline & $p<0.01 *$ \\
\hline $40 \times 300$ & $428.4 \pm 30.6^{\mathrm{a}}$ \\
\hline $60 \times 300$ & $451.9 \pm 45.5^{\mathrm{a}}$ \\
\hline $80 \times 300$ & $\begin{array}{c}587.1 \pm 17.5^{\mathrm{b}} \\
p=0.08\end{array}$ \\
\hline $40 \times 600$ & $442.5 \pm 36.8^{a}$ \\
\hline $60 \times 600$ & $477.0 \pm 44.0^{\mathrm{a}}$ \\
\hline $80 \times 600$ & $535.1 \pm 12.7^{\mathrm{a}}$ \\
\hline \multicolumn{2}{|c|}{ Temperature, ${ }^{\circ} \mathrm{C} \times$ irradiation time, $\min$} \\
\hline & $p<0.01 *$ \\
\hline $40 \times 5$ & $438.6 \pm 29.3^{a}$ \\
\hline $60 \times 5$ & $453.2 \pm 46.8^{\mathrm{a}}$ \\
\hline $80 \times 5$ & $\begin{array}{c}583.7 \pm 10.8^{\mathrm{b}} \\
p=0.11\end{array}$ \\
\hline $40 \times 10$ & $432.3 \pm 38.0^{\mathrm{a}}$ \\
\hline $60 \times 10$ & $475.8 \pm 42.7^{\mathrm{a}}$ \\
\hline $80 \times 10$ & $538.5 \pm 19.6^{a}$ \\
\hline \multicolumn{2}{|c|}{ Microwave power, $\mathrm{W} \times$ irradiation time, $\min$} \\
\hline & $p=0.42$ \\
\hline $300 \times 5$ & $465.0 \pm 30.3^{a}$ \\
\hline $600 \times 5$ & $\begin{array}{c}499.4 \pm 29.0^{\mathrm{a}} \\
p=0.16\end{array}$ \\
\hline $300 \times 10$ & $513.3 \pm 31.9^{a}$ \\
\hline $600 \times 10$ & $470.3 \pm 28.2^{a}$ \\
\hline
\end{tabular}

Results are expressed as LS mean \pm SE. * Statistically significant factor at $95 \%$ confidence level. Means with the same letter within the column are not significantly different at $p \leq 0.05$.

Acetone $(30 \%)$ proved to be the most effective solvent for isolation of polyphenols from fennel seeds, followed by water and 30\% ethanol. These results are in accordance with a previous study on optimization of MAE of nettle leaves' polyphenols [15]. Sulaiman et al. (2011) [36] reported that when compared to aqueous ethanol and aqueous methanol and water, $70 \%$ aqueous acetone was the most effective solvent for recovery of polyphenols from vegetables. Generally, aqueous solvent systems are considered the most effective for polyphenols' isolation due to the water soluble nature of these compounds and simultaneous ability of organic solvent component to penetrate into plant cell structure and improve extraction [37]. Additionally, acetone, unlike the ethanol or methanol, has the ability to inhibit and break the interactions between polyphenols and proteins and/or carbohydrates that are present in the outer shell of fennel seeds, thus preventing the formation of insoluble complexes and improving the extraction yield [38,39].

Application of higher temperatures in MAE resulted in the increase in TPC, producing the highest yields at $80^{\circ} \mathrm{C}$. This trend can be related to the enhanced penetration of the solvent into the sample matrix at elevated temperatures, especially since fennel seeds have a firm structure, which makes the extraction process at lower temperatures less effective. Also, it can be observed that ethanolic extracts, which gave the lowest TPC values at lower extraction temperatures, reached a phenolic content comparable to acetone extracts at $80^{\circ} \mathrm{C}$. The increase in TPC and flavonoids content in fennel seeds extracts with temperature elevation was also observed in the study by Angelov and Boyadzhieva (2016) [40] and Repajić et al. (2020) [41], where TPC values in fennel seeds were almost $45 \%$ higher at $110^{\circ} \mathrm{C}$ than at $80^{\circ} \mathrm{C}$ during pressurized liquid extraction. On the other hand, prolonged exposure to high temperatures may lead to degradation of phenolic compounds due to oxidation, decomposition and/or polymerization processes [14]. Therefore, it is necessary to observe the effect of temperature in relation to the exposure time. Obtained results have 
shown that irradiation time itself didn't have significant influence on TPC content of fennel seeds, therefore implying that shorter irradiation time $(5 \mathrm{~min})$ had the same efficiency as the longer one (10 $\mathrm{min})$. However, when irradiation time was observed in the context of applied temperature, shorter exposure at elevated temperature significantly increased TPC. Similar conclusions have been made by Alara et al. (2021) [42] for the effect of irradiation time on MAE of polyphenols from Carica papaya leaves, reporting $4 \mathrm{~min}$ to be the optimal extraction time, while further prolongation to $10 \mathrm{~min}$ caused degradation of polyphenols. An optimal irradiation time of $4 \mathrm{~min}$ was also reported for MAE of pomegranate peels [31], while 5 min was found to be optimal for MAE of chlorogenic acids from green coffee beans [43]. One of the main advantages of MAE is accelerated solubility of phenolic compounds due to exposure to microwave irradiation and elevated temperatures, which results in faster reaching of the extraction equilibrium when compared to conventional techniques [44].

Microwave power had no significant effect on the TPC yield of fennel seeds. The applied microwave power directly induces the microwave heating of the extraction feed, therefore resulting in temperature elevation. However, during our experiments, temperature was kept constant throughout the whole extraction process; therefore, selected microwave power was applied only in short time periods needed to keep the temperature constant. Similar conclusions have been made in previous studies on Pistacia lentiscus L. fruit and leaves and nettle leaves [14,15], where experiments were done with temperature as a fixed extraction parameter, as in the present study. Although in individual experiments the highest TPC was observed in extract produced by $30 \%$ acetone, at $60{ }^{\circ} \mathrm{C}$ after $10 \mathrm{~min}$, results of the statistical analysis showed a different trend. Therefore, based on the results of statistical analysis, the highest TPC values were obtained with $30 \%$ acetone as extraction solvent, at the highest temperature $\left(80^{\circ} \mathrm{C}\right)$ during 5 min exposure to microwave irradiation at $300 \mathrm{~W}$.

\subsection{Phenolic Characterization and Antioxidant Capacity of MAE and CE Extracts}

In order to observe the influence of MAE on the overall quality of obtained extract, optimized MAE extract of fennel seeds polyphenols was analyzed for its phenolic composition by UPLC/ESI-MS ${ }^{2}$ and antioxidant capacity by ORAC, and it was compared to CE (Table 3).

Table 3. Phenolic profile, TPC and ORAC values of fennel seeds extracts obtained under optimized MAE conditions $\left(80^{\circ} \mathrm{C}, 5 \mathrm{~min}, 300 \mathrm{~W}\right.$ with $30 \%$ acetone $)$ and $\mathrm{CE}$.

\begin{tabular}{|c|c|c|c|c|c|}
\hline & & $\begin{array}{l}\text { Precursor Ion } \\
\qquad \mathrm{m} / \mathrm{z}\end{array}$ & $\begin{array}{l}\text { Product Ion } \\
\qquad m / z\end{array}$ & $\begin{array}{c}\text { MAE } \\
(\mathrm{mg} / 100 \mathrm{~g})\end{array}$ & $\begin{array}{c}\mathrm{CE} \\
(\mathrm{mg} / 100 \mathrm{~g})\end{array}$ \\
\hline \multirow[t]{2}{*}{1} & $\begin{array}{l}\text { Benzoic acids } \\
p \text {-hydroxybenzoic acid-O-glucoside }\end{array}$ & 299 & 137 & $19.0 \pm 0.2$ & $17.0 \pm 0.2$ \\
\hline & Cinnamic acids & & & & \\
\hline 2 & Rosmarinic acid * & 359 & 197,179 & $7.9 \pm 0.1$ & $18.3 \pm 0.2$ \\
\hline 3 & Neochlorogenic acid & 353 & 191,179 & $25.4 \pm 0.6$ & $78.8 \pm 2.1$ \\
\hline 4 & Chlorogenic acid * & 353 & 191,179 & $60.4 \pm 1.2$ & $81.6 \pm 2.1$ \\
\hline 5 & Dicaffeoylquinic acid derivate & 515 & 353 & $20.5 \pm 0.2$ & $60.3 \pm 1.8$ \\
\hline 6 & Caffeoylquinic acid derivate 1 & 353 & 191 & $20.0 \pm 0.2$ & $31.6 \pm 1.2$ \\
\hline 7 & Caffeoylquinic acid derivate 2 & 353 & 191 & $60.2 \pm 1.4$ & $83.8 \pm 2.4$ \\
\hline 8 & Feruloylquinic acid derivate 1 & 367 & 193 & $1.4 \pm 0.0$ & $3.8 \pm 0.1$ \\
\hline 9 & Feruloylquinic acid derivate 2 & 367 & 193 & $6.8 \pm 0.1$ & $10.9 \pm 0.2$ \\
\hline \multirow[t]{2}{*}{10} & $p$-coumaroylquinic acid derivate & 337 & 191 & $4.6 \pm 0.2$ & $6.0 \pm 0.2$ \\
\hline & Flavonols & & & & \\
\hline 11 & Rutin * & 611 & 303 & $25.0 \pm 0.6$ & $54.3 \pm 1.3$ \\
\hline 12 & Kaempferol-3-rutinoside * & 595 & 287 & $27.4 \pm 0.8$ & $53.3 \pm 1.3$ \\
\hline
\end{tabular}


Table 3. Cont.

\begin{tabular}{|c|c|c|c|c|c|}
\hline & & $\begin{array}{l}\text { Precursor Ion } \\
\qquad \mathrm{m} / z\end{array}$ & $\begin{array}{l}\text { Product Ion } \\
\qquad \mathrm{m} / \mathrm{z}\end{array}$ & $\begin{array}{c}\text { MAE } \\
(\mathrm{mg} / 100 \mathrm{~g})\end{array}$ & $\begin{array}{c}\mathrm{CE} \\
(\mathrm{mg} / 100 \mathrm{~g})\end{array}$ \\
\hline 13 & Isorhamnetin hexoside 1 & 479 & 317 & $2.2 \pm 0.1$ & $3.4 \pm 0.1$ \\
\hline 14 & Isorhamnetin hexoside 2 & 479 & 317 & $2.7 \pm 0.1$ & $4.0 \pm 0.1$ \\
\hline 15 & Quercetin glucuronide & 479 & 303 & $52.4 \pm 1.2$ & $103.0 \pm 4.6$ \\
\hline 16 & Quercetin hexoside & 465 & 303 & $14.5 \pm 0.2$ & $32.4 \pm 0.7$ \\
\hline 17 & Quercetin-3-glucoside * & 465 & 303 & $18.0 \pm 0.2$ & $37.5 \pm 1.2$ \\
\hline 18 & Kaempferol glucuronide & 463 & 287 & $72.1 \pm 1.8$ & $155.6 \pm 7.5$ \\
\hline 19 & Kaempferol hexoside & 449 & 287 & $12.3 \pm 0.1$ & $22.2 \pm 0.7$ \\
\hline 20 & $\begin{array}{l}\text { Flavones } \\
\text { Apigenin glucuronide }\end{array}$ & 447 & 271 & $8.4 \pm 0.1$ & $6.0 \pm 0.1$ \\
\hline \multirow[t]{4}{*}{21} & $\begin{array}{l}\text { Coumarins } \\
\text { Esculetin hexoside }\end{array}$ & 339 & 177 & $3.8 \pm 0.1$ & $6.8 \pm 0.2$ \\
\hline & $\begin{array}{l}\text { Total UPLC/ESI- MS } 2 \text { identified } \\
\text { compounds }(\mathrm{mg} / 100 \mathrm{~g})\end{array}$ & & & $465.0 \pm 0.9^{\mathrm{a}}$ & $870.5 \pm 0.2^{b}$ \\
\hline & TPC (mg GAE/100 g) & & & $608.2 \pm 4.9^{a}$ & $878.6 \pm 26.1^{b}$ \\
\hline & ORAC ( $\mu \mathrm{mol}$ TE/100 g) & & & $830.2 \pm 5.7^{a}$ & $838.0 \pm 8.5^{a}$ \\
\hline
\end{tabular}

* identification confirmed using authentic standards. Results are expressed as mean \pm standard deviation. Means with the same letter within the row are not significantly different at $p \leq 0.05$ by Tukey's HSD test.

A total of 21 phenolic compounds were identified by UPLC/ESI-MS ${ }^{2}$, comprising benzoic and cinnamic acids, flavonols, flavones and coumarins (Figure 1). Qualitatively, phenolic composition did not differ between the two analyzed extracts.
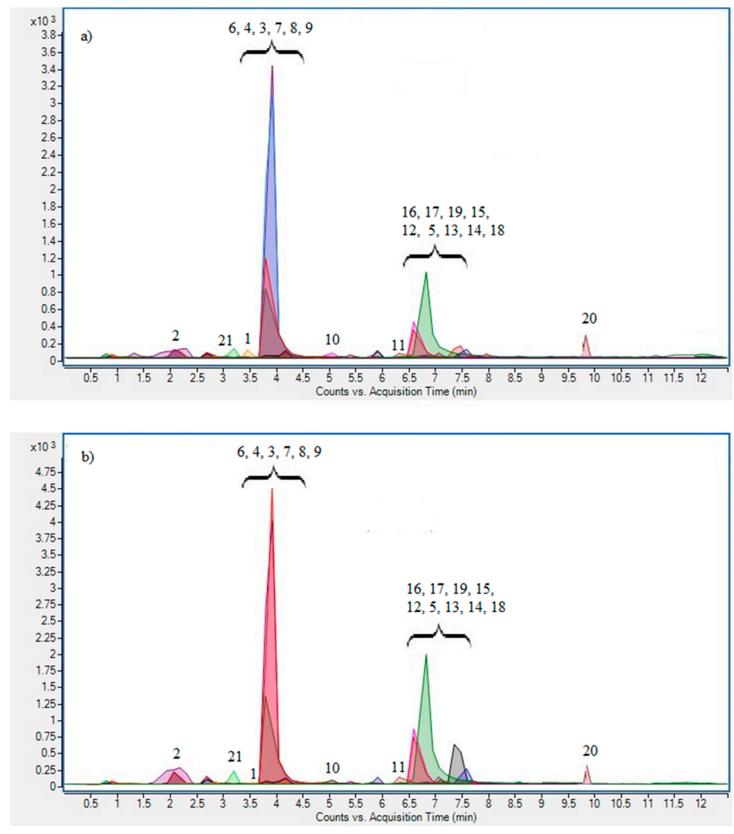

Figure 1. UPLC/ESI-MS ${ }^{2}$ chromatogram in MRM acquisition from fennel seed extracts obtained under optimized MAE conditions (a), and CE (b): (1) p-hydroxybenzoic acid-O-glucoside, (2) Rosmarinic acid, (3) Neochlorogenic acid, (4) Chlorogenic acid, (5) Dicaffeoylquinic acid derivate, (6), Caffeoylquinic acid derivate 1, (7) Caffeoylquinic acid derivate 2, (8) Feruloylquinic acid derivate 1, (9) Feruloylquinic acid derivate 2, (10) p-coumaroylquinic acid derivate, (11) Rutin, (12) Kaempferol3-rutinoside, (13) Isorhamnetin hexoside 1, (14) Isorhamnetin hexoside 2, (15) Quercetin glucuronide, (16) Quercetin hexoside, (17) Quercetin-3-glucoside, (18) Kaempferol glucuronide, (19) Kaempferol hexoside, (20) Apigenin glucuronide, (21) Esculetin hexoside. 
Among the phenolic acids, the predominant class in fennel seeds extracts were cinnamic acids. In this class, compounds 2 and 4 were identified by authentic standards as rosmarinic and chlorogenic acid. Compound 3 showed the same fragmentation pattern as compound 4, with a molecular ion at $m / z 353$ and a fragment ion at $m / z 191$ corresponding to the quinic acid moiety, indicating the structure of caffeoylquinic acid [45]. Since compound 4 was identified as chlorogenic (3-O-caffeoylquinic) acid by the authentic standard, compound 3 was assigned as 5-O-caffeoylquinic or neochlorogenic acid due to its higher polarity and similar fragmentation pathway. Similar pathways were observed for compounds 6 and 7, which were therefore tentatively identified as caffeoylquinic acid derivates 1 and 2. Compound 5, on the other hand, showed a molecular ion at $m / z 515$, while a fragment ion at $m / z 353$ corresponded to caffeoylquinic moiety, indicating the $\mathrm{C}_{25} \mathrm{H}_{24} \mathrm{O}_{12}$ formula corresponding to the structure of dicaffeoylquinic acid [46]. Compounds 8 and 9 had molecular ions at $m / z 367$ and fragment ions at $m / z$ 193, suggesting the molecular structure of feruloylquinic acids [45]. $\mathrm{MS}^{2}$ spectra of compound $\mathbf{1 0}$ yielded a molecular ion at $m / z 337$ with a fragment ion at $m / z$ 191. This fragmentation pattern is in accordance with one reported for $p$-coumaroylquinic acids [5]. Regarding the benzoic acids, only one was detected in fennel seed extracts. It was characterized with a molecular ion at $m / z 299$ and a fragment ion at $m / z$ 137. A loss of -162 amu indicated the cleavage of hexose sugar, resulting in a phenolic acid fragment, so compound $\mathbf{1}$ was assigned as $p$-hydroxybenzoic acid-O-glucoside, according to the previous report on its identification in fennel seeds by Parejo et al. (2004) [5]. The most abundant polyphenolic class in fennel seeds extracts were flavonols. Among them, compounds 11, 12 and 17 were identified by commercial standards as rutin, kaempferol-3-rutinoside and quercetin-3-glucoside, respectively. Compounds 13 and 14 showed a fragment ion at $m / z$ 317, characteristic for isorhamnetin, and were tentatively identified as hexosides due to loss of $162 \mathrm{amu}$, corresponding to the hexose moiety. Compounds $\mathbf{1 5}$ and $\mathbf{1 6}$ were assigned as quercetin glycosides, namely quercetin glucuronide and quercetin hexoside, due to their fragment ion at $m / z 303$ and molecular ions at $m / z 479$ and 465. Similar fragmentations were observed for compounds 18 and 19 , with fragment ions at $m / z 287$ related to kaempferol, and were therefore assigned as kaempferol glucuronide and hexoside, respectively. In the class of flavones in fennel seeds, one compound was determined and, due to the fragment ion at $m / z 271$ and characteristic loss of 176 amu corresponding to glucuronic acid, assigned as apigenin glucuronide. Compound 21, a representative of the coumarines class, was tentatively identified as esculetin hexoside, due to the characteristic ion at $m / z 271$ and neutral loss of 162 amu for hexose sugar. Similar composition including mainly cinnamic acids and flavonols and their derivates was reported for fennel seeds in previous studies $[5,47]$. Regarding the influence of the extraction technique, it can be observed that CE extract had higher concentrations of most of the identified compounds, with the exception of benzoic acids and flavones. Therefore, the obtained content of total identified compounds as well as spectrofotometrically determined TPC were lower when applying MAE as an advanced extraction technique in comparison to conventional 20 min reflux extraction. Hence, more intensive treatment of fennel seeds is required to isolate target compounds, indicating the impact of plant material morphology and firm structure. Similar conclusions were made by Leal et al. (2011) [48], where higher yield of extraction of bioactive compounds from fennel seeds was observed using the classical Soxhlet extraction in comparison with non-conventional UAE method. Rodriguez-Solana et al. (2013) [19] isolated more volatile compounds from fennel seeds using Soxhlet extraction when compared to pressurized liquid extraction, with practically no difference found between the concentrations of the estragole among extracts. This superiority of conventional extraction techniques could probably be attributed to the temperature effect, as the conventional Soxhlet technique applies temperatures above the boiling point of the solvent for a prolonged time, unlike the MAE, where $80{ }^{\circ} \mathrm{C}$ was applied only for short period of $5 \mathrm{~min}$. Therefore, the more intensive conditions of conventional techniques outperform the advanced ones for plant material with firm structure, such as the case with fennel seeds. An interesting observation can be made when comparing 
the sum of all identified individual compounds with TPC between the two techniques. The difference between the amount of identified phenols and TPC is greater in the MAE extract, while those two values are almost the same in the CE extract. It could be related to the selectivity of extraction methods towards the isolation of polyphenols, meaning that microwave irradiation enhanced the isolation of other non-phenolic compounds such as chlorophylls, sugars, organic acids and proteins, which have been reported to interfere with Folin-Ciocalteu reagent $[49,50]$.

In order to observe the influence of the extraction method on the antioxidant capacity of fennel seeds extracts, ORAC assay has been applied, which is considered to be one of the most biologically relevant assays. As an assay based on hydrogen atom transfer, it is preferred over a single electron reaction mechanism (FRAP, ABTS and DPPH) because the peroxyl radical is the predominant free radical found in lipid oxidation in foods and biological systems $[49,51]$. Although the CE extract contained more phenolic compounds than MAE extract, the ORAC value did not differ significantly between them, as can be seen in Table 3. This corroborates the assumption of the presence of non-phenolic compounds in MAE extract, which possess the antioxidant activity. The ORAC values obtained in analyzed extracts are lower than those reported for fennel essential oil [52] but higher than ones reported for fennel leaves extract [53] and raw fennel bulb vegetable [54].

\subsection{Antimicrobial Activity of Fennel Seeds Extract}

Assuming that the extract with the highest TPC also has the highest biological activity, the antimicrobial activity was determined only for the optimal CE extract. The results are presented in Table 4.

Table 4. Antimicrobial activity of the CE fennel seeds extract expressed as MIC and MBC/MFC.

\begin{tabular}{lcc}
\hline \multicolumn{1}{c}{ Microbial Strain } & $\begin{array}{c}\text { MIC } \\
(\mathbf{m g} / \mathbf{m L})\end{array}$ & $\begin{array}{c}\text { MBC/MFC } \\
(\mathbf{m g} / \mathbf{m L})\end{array}$ \\
\hline Staphylococcus aureus ATCC25923 & nd & nd \\
Listeria innocua ŽM39 & nd & nd \\
Escherichia coli ATCC11229 & nd & nd \\
Pseudomonas fragi ATCC4973 & 2 & nd \\
Shewanella putrefaciens ŽM654 & 4 & nd \\
Shewanella xiamenensis ŽM655 & nd & nd \\
Shewanella baltica NCTC10735 & nd & nd \\
Campylobacter jejuni NCTC11168 & 2 & 4 \\
Candida albicans ZIM2202 & nd & nd \\
Pichia anomala ZIM1769 & nd & nd \\
\hline
\end{tabular}

nd-not determined, $>4 \mathrm{mg} / \mathrm{mL}$.

To test the antimicrobial activity of the fennel seed CE extract, Gram-positive and Gram-negative bacterial strains and two fungi strains, important in food technology as foodborne pathogens or food spoilage microorganisms, were used. The fennel seeds extract showed weak antimicrobial activity against the tested microbial strains. Antimicrobial activity could be determined only for P. fragi, S. putrefaciens and C. jejuni strains, with MIC of $2-4 \mathrm{mg} / \mathrm{mL}$, which is not considered to be a good antimicrobial efficacy based on Simões et al. (2009) [55], where a limit of $1 \mathrm{mg} / \mathrm{mL}$ is set. No inhibitory effect was observed on other selected test microorganisms. However, although Gram-negative bacteria are considered more resistant to antimicrobial agents in comparison with Gram-positive bacteria, the fennel seeds extract showed antimicrobial activity against some Gram-negative strains, while no activity against Gram-positive S. aureus and L. innocua was observed. Such results might be related to the high content of glycosylated phenolic compounds. Huynh et al. (2018) [56] reported the impact of microbial enzymes on the form of phenols by deglycosylating them into aglycones, thereby increasing their antimicrobial activity. Sterniša et al. (2020) [57] also attributed an important role to the high enzymatic activities of Pseudomonas and Shewanella strains on the antimicrobial activity of phenolic glycosides in nettle and oregano extracts. 
Furthermore, it is suggested that flavonoids could inhibit the microbial growth by inhibiting their nucleic acid synthesis, cytoplasmic membrane function and energy metabolism [35].

Antimicrobial activity of fennel seeds has been studied mainly in the context of their essential oils, while few studies included extracts. Anwar et al. (2009) [34] reported considerable antimicrobial activity of fennel essential oil against Gram-positive bacteria, while fennel extracts showed no activity. On the contrary, Roby et al. (2013) [32] reported good antimicrobial activity of both fennel essential oil and extracts, especially against $B$. cereus and A. flavus, while Salami et al. (2016) [35] showed very good antibacterial activity of methanol fennel seed extract against E. coli, S. aureus, Salmonella Typhimurium and Bacillus subtilis with MIC values below or equal to $500 \mu \mathrm{g} / \mathrm{mL}$. Mahady et al. (2005) [58] reported very good antimicrobial activity against Helicobacter pylori (MIC $=50 \mu \mathrm{g} / \mathrm{mL}$ ).

\section{Conclusions}

Although microwave-assisted extraction is an effective "green « approach for the isolation of plant polyphenols, the results of this study showed that conventional heat-reflux provided greater amounts of extracted compounds from fennel seeds. Such results may be attributed to the material characteristics, as seeds are characterized by a firm shell structure that requires more intensive treatment to achieve greater recovery of bioactives. Taking that into consideration, future studies should be done in terms of combining different approaches, such as enzymatic pretreatment in combination with advanced extraction techniques, in order to improve the extraction yield. Regardless of the extraction method, aqueous acetone proved to be the most effective solvent for isolation of fennel polyphenols, producing extracts rich in polyphenols belonging mainly to the classes of cinnamic acids and flavonol glycosides. Although the fennel extract was rich in polyphenols and characterized with high antioxidant capacity, its antimicrobial activity was weak. Nevertheless, its activity against $P$. fragi, which is one of the most important meat and fish spoilage microorganisms, and against $C$. jejuni, which is one of the most important food-borne pathogens, should be mentioned. Therefore, the synergistic action of its antimicrobial properties and high antioxidant capacity makes fennel seeds a promising natural product for the food and nutraceutical industry. However, this study revealed the necessity for future steps for better evaluation of fennel seed's potential, which should include more parameters in evaluation of researchers' extraction procedure accompanied by adequate statistical analysis, as well as more detailed research of its antimicrobial activity.

Supplementary Materials: The following supporting information can be downloaded at: https: / /www.mdpi.com/article/10.3390/pr10030510/s1, File S1: MS spectra of tentatively identified phenolic compounds.

Author Contributions: Conceptualization, I.E.G., S.S.M. and V.D.-U.; data curation, V.M. and Z.Z.; formal analysis, V.M., Z.Z., S.P. and M.S.; funding acquisition, S.S.M. and V.D.-U.; investigation, V.M., M.R., Z.Z., S.P. and M.S.; methodology, I.E.G.; project administration, S.S.M. and V.D.-U.; writingoriginal draft, V.M. and I.E.G.; writing-review \& editing, I.E.G. and M.R.. All authors have read and agreed to the published version of the manuscript.

Funding: This research was funded by the Croatian Science Foundation project, grant number IP-01-2018-4924, Slovenian Research Agency (P4-0116) and CEEPUS network CIII-HR-0306-12-1920M-140167, For Safe and Healthy Food in Middle Europe.

Institutional Review Board Statement: Not applicable.

Informed Consent Statement: Not applicable.

Acknowledgments: Authors are thankful to Zoran Herceg for the support in providing laboratory equipment used for the experiment through the project "Equipping the Semi-Industrial Practice Laboratory for the Development of New Food Technologies" (KK.01.1.1.02.0001) financed by the European Union. 
Conflicts of Interest: The authors declare no conflict of interest. The funders had no role in the design of the study; in the collection, analyses, or interpretation of data; in the writing of the manuscript, or in the decision to publish the results.

\section{References}

1. Akhtar, I.; Javad, S.; Ansari, M.; Ghaffar, N.; Tariq, A. Process optimization for microwave assisted extraction of Foeniculum vulgare Mill using response surface methodology. J. King Saud. Univ. 2020, 32, 1451-1458. [CrossRef]

2. Badgujar, S.B.; Patel, V.V.; Bandivdekar, A.H. Foeniculum vulgare Mill: A review of its botany, phytochemistry, pharmacology, contemporary application, and toxicology. Biomed Res. Int. 2014, 2014, 842674. [CrossRef] [PubMed]

3. Rather, M.A.; Dar, B.A.; Sofi, S.N.; Bhat, B.A.; Qurishi, M.A. Foeniculum vulgare: A comprehensive review of its traditional use, phytochemistry, pharmacology, and safety. Arab. J. Chem. 2016, 9, S1574-S1583. [CrossRef]

4. Balbino, S.; Repajić, M.; Obranović, M.; Medved, A.M.; Tonković, P.; Dragović-Uzelac, V. Characterization of lipid fraction of Apiaceae family seed spices: Impact of species and extraction method. J. Appl. Res. Med. Aromat. Plants 2021, $25,100326$. [CrossRef]

5. Parejo, I.; Jauregui, O.; Sánchez-Rabaneda, F.; Viladomat, F.; Bastida, J.; Codina, C. Separation and characterization of phenolic compounds in fennel (Foeniculum vulgare) using liquid chromatography-negative electrospray ionization tandem mass spectrometry. J. Agric. Food Chem. 2004, 52, 3679-3687. [CrossRef]

6. Azmir, J.; Zaidul, I.S.M.; Rahman, M.M.; Sharif, K.M.; Mohamed, A.; Sahena, F.; Jahurul, M.H.A.; Ghafoor, K.; Norulaini, N.A.N.; Omar, A.K.M. Techniques for extraction of bioactive compounds from plant materials: A review. J. Food Eng. 2013, 117, 426-436. [CrossRef]

7. Manousi, N.; Sarakatsianos, I.; Samanidou, V. Extraction techniques of phenolic compounds and other bioactive compounds from medicinal and aromatic plants. In Engineering Tools in the Beverage Industry; Elsevier: Amsterdam, The Netherlands, 2019; pp. 283-314.

8. Lovrić, V.; Putnik, P.; Bursać Kovačević, D.; Jukić, M.; Dragović-Uzelac, V. The Effect of Microwave-Assisted Extraction on the Phenolic Compounds and Antioxidant Capacity of Blackthorn Flowers. Food Technol. Biotechnol. 2017, 55, 243-250. [CrossRef]

9. Ismail-Suhaimy, N.W.; Gani, S.S.A.; Zaidan, U.H.; Halmi, M.I.E.; Bawon, P. Optimizing conditions for microwave-assisted extraction of polyphenolic content and antioxidant activity of Barleria lupulina lindl. Plants 2021, 10, 682. [CrossRef]

10. Mellinas, A.C.; Jiménez, A.; Garrigós, M.C. Optimization of microwave-assisted extraction of cocoa bean shell waste and evaluation of its antioxidant, physicochemical and functional properties. LWT 2020, 127, 109361. [CrossRef]

11. Dobrinčić, A.; Repajic, M.; Elez Garofulić, I.; Tuđen, L.; Dragović-Uzelac, V.; Levaj, B. Comparison of Different Extraction Methods for the Recovery of Olive Leaves Polyphenols. Processes 2020, 8, 1008. [CrossRef]

12. Dobroslavić, E.; Elez Garofulić, I.; Zorić, Z.; Pedisić, S.; Dragović-Uzelac, V. Polyphenolic Characterization and Antioxidant Capacity of Laurus nobilis L. Leaf Extracts Obtained by Green and Conventional Extraction Techniques. Processes 2021, 9, 1840. [CrossRef]

13. Elez Garofulić, I.; Dragović-Uzelac, V.; Režek Jambrak, A.; Jukić, M. The effect of microwave assisted extraction on the isolation of anthocyanins and phenolic acids from sour cherry Marasca (Prunus cerasus var. Marasca). J. Food Eng. 2013, 117, 437-442. [CrossRef]

14. Elez Garofulić, I.; Kruk, V.; Martić, A.; Martić, I.; Zorić, Z.; Pedisić, S.; Dragović, S.; Dragović-Uzelac, V. Evaluation of Polyphenolic Profile and Antioxidant Activity of Pistacia lentiscus L. Leaves and Fruit Extract Obtained by Optimized Microwave-Assisted Extraction. Foods 2020, 9, 1556. [CrossRef] [PubMed]

15. Elez Garofulić, I.; Malin, V.; Repajić, M.; Zorić, Z.; Pedisić, S.; Sterniša, M.; Smole Možina, S.; Dragović-Uzelac, V. Phenolic Profile, Antioxidant Capacity and Antimicrobial Activity of Nettle Leaves Extracts Obtained by Advanced Extraction Techniques. Molecules 2021, 26, 6153. [CrossRef] [PubMed]

16. Dragović-Uzelac, V.; Garofulić, I.E.; Jukić, M.; Penić, M.; Dent, M. The influence of microwave-assisted extraction on the isolation of sage (Salvia officinalis L.) Polyphenols. Food Technol. Biotechnol. 2012, 50, 377-383.

17. Rezaei, S.; Ebadi, M.-T.; Ghobadian, B.; Ghomi, H. Optimization of DBD-Plasma assisted hydro-distillation for essential oil extraction of fennel (Foeniculum vulgare Mill.) seed and spearmint (Mentha spicata L.) leaf. J. Appl. Res. Med. Aromat. Plants 2021, 24, 100300. [CrossRef]

18. Koşar, M.; Özek, T.; Kürkçüoglu, M.; Başer, K.H.C. Comparison of microwave-assisted hydrodistillation and hydrodistillation methods for the fruit essential oils of Foeniculum vulgare. J. Essent. Oil Res. 2007, 19, 426-429. [CrossRef]

19. Rodríguez-Solana, R.; Salgado, J.M.; Domínguez, J.M.; Cortés-Diéguez, S. Characterization of fennel extracts and quantification of estragole: Optimization and comparison of accelerated solvent extraction and Soxhlet techniques. Ind. Crops Prod. 2014, 52, 528-536. [CrossRef]

20. Boudraa, H.; Kadri, N.; Mouni, L.; Madani, K. Microwave-assisted hydrodistillation of essential oil from fennel seeds: Optimization using Plackett-Burman design and response surface methodology. J. Appl. Res. Med. Aromat. Plants 2021, $23,100307$. [CrossRef]

21. Mirdehghan Ashkezari, S.M.; Bahmanyar, H.; Azizpour, H.; Mohammadi, M.; Najafipour, I. Investigation of Operating Parameters on Ultrasound-Assisted Extraction of Anethole in Fennel Essential oil. J. Chem. Pet. Eng. 2021, 55, 339-351. 
22. Mokhtari, L.; Ghoreishi, S.M. Supercritical carbon dioxide extraction of trans-anethole from Foeniculum vulgare (fennel) seeds: Optimization of operating conditions through response surface methodology and genetic algorithm. J. CO 2 Util. 2019, 30, 1-10. [CrossRef]

23. Hatami, T.; Johner, J.C.F.; Meireles, M.A.A. Extraction and fractionation of fennel using supercritical fluid extraction assisted by cold pressing. Ind. Crops Prod. 2018, 123, 661-666. [CrossRef]

24. Hatami, T.; Johner, J.C.F.; Meireles, M.A.A. Investigating the effects of grinding time and grinding load on content of terpenes in extract from fennel obtained by supercritical fluid extraction. Ind. Crops Prod. 2017, 109, 85-91. [CrossRef]

25. Shortle, E.; O'grady, M.N.; Gilroy, D.; Furey, A.; Quinn, N.; Kerry, J.P. Influence of extraction technique on the anti-oxidative potential of hawthorn (Crataegus monogyna) extracts in bovine muscle homogenates. Meat Sci. 2014, 98, 828-834. [CrossRef] [PubMed]

26. Elez Garofulić, I.; Zorić, Z.; Pedisić, S.; Brnčić, M.; Dragović-Uzelac, V. UPLC-MS2 Profiling of Blackthorn Flower Polyphenols Isolated by Ultrasound-Assisted Extraction. J. Food Sci. 2018, 83, 2782-2789. [CrossRef] [PubMed]

27. Klančnik, A.; Piskernik, S.; Jeršek, B.; Možina, S.S. Evaluation of diffusion and dilution methods to determine the antibacterial activity of plant extracts. J. Microbiol. Methods 2010, 81, 121-126. [CrossRef]

28. Zhao, C.N.; Zhang, J.J.; Li, Y.; Meng, X.; Li, H. Bin Microwave-assisted extraction of phenolic compounds from melastoma sanguineum fruit: Optimization and identification. Molecules 2018, 23, 2498. [CrossRef]

29. Dent, M.; Dragovic-Uzelac, V.; Garofulic, I.E.; Bosiljkov, T.; Ježek, D.; Brncic, M. Comparison of conventional and ultrasoundassisted extraction techniques on mass fraction of phenolic compounds from sage (Salvia officinalis L.). Chem. Biochem. Eng. Q. 2015, 29, 475-484. [CrossRef]

30. Dent, M.; Dragović-Uzelac, V.; Penić, M.; Bosiljkov, T.; Levaj, B. The effect of extraction solvents, temperature and time on the composition and mass fraction of polyphenols in Dalmatian wild sage (Salvia officinalis L.) extracts. Food Technol. Biotechnol. 2013, 51, 84-91.

31. Kaderides, K.; Papaoikonomou, L.; Serafim, M.; Goula, A.M. Microwave-assisted extraction of phenolics from pomegranate peels: Optimization, kinetics, and comparison with ultrasounds extraction. Chem. Eng. Process. Process Intensif. 2019, $137,1-11$. [CrossRef]

32. Roby, M.H.H.; Sarhan, M.A.; Selim, K.A.-H.; Khalel, K.I. Antioxidant and antimicrobial activities of essential oil and extracts of fennel (Foeniculum vulgare L.) and chamomile (Matricaria chamomilla L.). Ind. Crops Prod. 2013, 44, 437-445. [CrossRef]

33. Repajić, M.; Ekić, S.; Kruk, V.; Dragović-Uzelac, V. Effect of accelerated solvent extraction conditions on the isolation of bioactive compounds from fennel (Foeniculum vulgare Mill.) seeds. Hrvat. Časopis Prehrambenu Tehnol. Biotehnol. Nutr. 2020, 15, 102-106. [CrossRef]

34. Anwar, F.; Ali, M.; Hussain, A.I.; Shahid, M. Antioxidant and antimicrobial activities of essential oil and extracts of fennel (Foeniculum vulgare Mill.) seeds from Pakistan. Flavour Fragr. J. 2009, 24, 170-176. [CrossRef]

35. Salami, M.; Rahimmalek, M.; Ehtemam, M.H.; Sabzalian, M.R. Variation in bioactive contents and anatomical characteristics of different fennel (Foeniculum vulgare Mill.) populations as affected by self-pollination. J. Appl. Bot. Food Qual. 2016, 89, 38-48.

36. Sulaiman, S.F.; Sajak, A.A.B.; Ooi, K.L.; Seow, E.M. Effect of solvents in extracting polyphenols and antioxidants of selected raw vegetables. J. Food Compos. Anal. 2011, 24, 506-515. [CrossRef]

37. Moure, A.; Cruz, J.M.; Franco, D.; Domínguez, J.M.; Sineiro, J.; Domínguez, H.; Núñez, M.J.; Parajó, J.C. Natural antioxidants from residual sources. Food Chem. 2001, 72, 145-171. [CrossRef]

38. Rocha-Guzmán, N.E.; Herzog, A.; González-Laredo, R.F.; Ibarra-Pérez, F.J.; Zambrano-Galván, G.; Gallegos-Infante, J.A. Antioxidant and antimutagenic activity of phenolic compounds in three different colour groups of common bean cultivars (Phaseolus vulgaris). Food Chem. 2007, 103, 521-527. [CrossRef]

39. Jakobek, L. Interactions of polyphenols with carbohydrates, lipids and proteins. Food Chem. 2015, 175, 556-567. [CrossRef]

40. Angelov, G.; Boyadzhieva, S. Extraction of fennel (Foeniculum vulgare) seeds: Process optimization and antioxidant capacity of the extracts. Chem. Biochem. Eng. Q. 2016, 30, 245-253. [CrossRef]

41. Repajić, M.; Cegledi, E.; Kruk, V.; Pedisić, S.; Çinar, F.; Kovačević, D.B.; Žutić, I.; Dragović-Uzelac, V. Accelerated solvent extraction as a green tool for the recovery of polyphenols and pigments fromwild nettle leaves. Processes 2020, 8, 803. [CrossRef]

42. Alara, O.R.; Abdurahman, N.H.; Ali, H.A.; Zain, N.M. Microwave-assisted extraction of phenolic compounds from Carica papaya leaves: An optimization study and LC-QTOF-MS analysis. Futur. Foods 2021, 3, 100035. [CrossRef]

43. Upadhyay, R.; Ramalakshmi, K.; Rao, L.J.M. Microwave-assisted extraction of chlorogenic acids from green coffee beans. Food Chem. 2012, 130, 184-188. [CrossRef]

44. Xu, D.-P.; Li, Y.; Meng, X.; Zhou, T.; Zhou, Y.; Zheng, J.; Zhang, J.-J.; Li, H.-B. Natural antioxidants in foods and medicinal plants: Extraction, assessment and resources. Int. J. Mol. Sci. 2017, 18, 96. [CrossRef] [PubMed]

45. Clifford, M.N.; Johnston, K.L.; Knight, S.; Kuhnert, N. Hierarchical scheme for LC-MSn identification of chlorogenic acids J. Agric. Food Chem. 2003, 51, 2900-2911. [CrossRef] [PubMed]

46. He, W.; Liu, X.; Xu, H.; Gong, Y.; Yuan, F.; Gao, Y. On-line HPLC-ABTS screening and HPLC-DAD-MS/MS identification of free radical scavengers in Gardenia (Gardenia jasminoides Ellis) fruit extracts. Food Chem. 2010, 123, 521-528. [CrossRef]

47. Zorić, Z.; Repajić, M.; Kruk, V.; Levaj, B.; Kovačević, D.B.; Jurčević, I.L.; Dragović-Uzelac, V. UPLC-MS/MS characterization of phenolic constituents in fennel seed extracts (Foeniculum vulgare Mill.). Proc. Nutr. Soc. 2020, 79. [CrossRef] 
48. Leal, P.F.; Almeida, T.S.; Prado, G.H.C.; Prado, J.M.; Meireles, M.A.A. Extraction kinetics and anethole content of fennel (Foeniculum vulgare) and anise seed (Pimpinella anisum) extracts obtained by soxhlet, ultrasound, percolation, centrifugation, and steam distillation. Sep. Sci. Technol. 2011, 46, 1848-1856. [CrossRef]

49. Prior, R.L.; Wu, X.; Schaich, K. Standardized Methods for the Determination of Antioxidant Capacity and Phenolics in Foods and Dietary Supplements. J. Agric. Food Chem. 2005, 53, 4290-4302. [CrossRef]

50. El-Hamidi, M.; Zaher, F.A.; El-Shami, S.M. Interaction of oilseed pigments and phospholipids in the determination of total phenolic compounds using the Folin-Ciocalteu reagent. Int. J. PharmTech Res. 2016, 9, 207-214.

51. Prior, R.L. Oxygen radical absorbance capacity (ORAC): New horizons in relating dietary antioxidants/bioactives and health benefits. J. Funct. Foods 2015, 18, 797-810. [CrossRef]

52. Moser, B.R.; Zheljazkov, V.D.; Bakota, E.L.; Evangelista, R.L.; Gawde, A.; Cantrell, C.L.; Winkler-Moser, J.K.; Hristov, A.N.; Astatkie, T.; Jeliazkova, E. Method for obtaining three products with different properties from fennel (Foeniculum vulgare) seed. Ind. Crops Prod. 2014, 60, 335-342. [CrossRef]

53. Pacifico, S.; Galasso, S.; Piccolella, S.; Kretschmer, N.; Pan, S.-P.; Nocera, P.; Lettieri, A.; Bauer, R.; Monaco, P. Winter wild fennel leaves as a source of anti-inflammatory and antioxidant polyphenols. Arab. J. Chem. 2018, 11, 513-524. [CrossRef]

54. Haytowitz, D.B.; Bhagwat, S. USDA Database for the Oxygen Radical Absorbance Capacity (ORAC) of Selected Foods, Release 2; U.S. Department of Agriculture: New York, NY, USA, 2010; 3, pp. 10-48.

55. Simoes, M.; Bennett, R.N.; Rosa, E.A.S. Understanding antimicrobial activities of phytochemicals against multidrug resistant bacteria and biofilms. Nat. Prod. Rep. 2009, 26, 746-757. [CrossRef]

56. Huynh, N.T.; Smagghe, G.; Gonzales, G.B.; Van Camp, J.; Raes, K. Bioconversion of Kaempferol and Quercetin Glucosides from Plant Sources Using Rhizopus spp. Fermentation 2018, 4, 102. [CrossRef]

57. Sterniša, M.; Bucar, F.; Kunert, O.; Možina, S.S. Targeting fish spoilers Pseudomonas and Shewanella with oregano and nettle extracts. Int. J. Food Microbiol. 2020, 328, 108664. [CrossRef] [PubMed]

58. Mahady, G.B.; Pendland, S.L.; Stoia, A.; Hamill, F.A.; Fabricant, D.; Dietz, B.M.; Chadwick, L.R. In vitro susceptibility of Helicobacter pylori to botanical extracts used traditionally for the treatment of gastrointestinal disorders. Phyther. Res. An Int. J. Devoted to Pharmacol. Toxicol. Eval. Nat. Prod. Deriv. 2005, 19, 988-991. 